\title{
Some relationships between elevation, physico- chemical variables and biota of intertidal rock pools
}

\author{
J. Huggett \& C. L. Griffiths \\ Zoology Department, University of Cape Town, Rondebosch 7700, South Africa
}

\begin{abstract}
Diurnal fluctuations in temperature and oxygen concentration were monitored in rock pools at different intertidal levels. All pools experienced 2 extremes during the day - an oxygen minimum, which occurred before dawn (or immediately before flooding after a nocturnal low tide) and a combined oxygen and temperature maximum, at about $1500 \mathrm{~h}$ (or before flooding after a daytime low tide). Temperature extremes were directly related to tidal elevation, but oxygen extremes were determined by the balance between exposure time, which decreased downshore, and the net rate of oxygen consumption or liberation by the biota. The largest fluctuations occurred in pools between midtide and low water neap levels, where diurnal ranges of $<20 \%$ to $>300 \%$ oxygen saturation were routine. Numbers of species colonizing rock pools declined linearly with elevation. The abiotic factors influencing the upward penetration of species probably differ with tidal level, reduced oxygen concentration probably being limiting in lowshore pools and temperature and salinity becoming more significant at higher levels. Rock pools can be grouped into 3 distinct vertical zones by cluster analysis of their biota. These zones correspond closely to the established patterns for intertidal communities subject to aerial exposure.
\end{abstract}

\section{INTRODUCTION}

Rock pools have long been recognized as constituting a specialized habitat within the intertidal zone, but as they are not aerially exposed they are usually excluded from studies of zonation. As a result few attempts have been made to describe the distribution patterns of their biota or to relate these to the fluctuating physico-chemical conditions to which the pools are subject.

Klugh (1924) attempted to relate the communities occurring in pools at various levels on the New Brunswick coast with the extremes of salinity, hydrogen ion concentration, light and temperature occurring within them. He concluded that temperature was the most important of these parameters, a view echoed by Johnson \& Skutch (1928), following a similar survey of the distribution of algae in intertidal pools in Maine.

Later workers, notably Stephenson et al. (1934), Pyefinch (1943), Ambler \& Chapman (1950) and Naylor \& Slinn (1958), measured diurnal variation in oxygen concentration in addition to temperature and $\mathrm{pH}$. They, too, found that pools high on the shore experi- enced progressively higher temperatures and continued to regard this as the most important factor controlling species composition. Dramatic fluctuations in oxygen concentration were, however, also recorded and the amplitude of these variations found to depend upon the density and proportions of plants and animals in the pools, as well as the period for which they were isolated from the sea. Pyefinch (1943) and Ambler \& Chapman (1950) also recognized that the time of day at which low tide occurred was critical in determining the extreme values attained for both temperature and oxygen concentration.

Daniel \& Boyden (1975) investigated diumal variations in $\mathrm{pH}$, carbon dioxide and salinity, as well as temperature and oxygen concentration, and placed special emphasis on night-time conditions. Temperature and oxygen concentration once more showed the greatest variation, displaying diurnal fluctuations similar to those reported by previous authors, and these were identified as being particularly important in controlling community structure.

In the most detailed study of conditions in tidal rock pools to date, Morris \& Taylor (1983) followed both 
diurnal and seasonal changes in temperature, $\mathrm{pH}$ salinity, oxygen concentration and carbon dioxide content in pools at different levels, as well as local variations in the physico-chemical regimes within individual pools. The most variable parameters were again temperature and oxygen concentration, and the amplitude of the fluctuations was found to be related to the heights of the pools on the shore. Extreme conditions reached within individual pools were dependent upon the time and height of the tide and the time of year, conditions being most extreme in summer.

The above, and other similar studies (reviewed by Newell 1979), have provided adequate data as to the manner in which physico-chemical conditions in individual rock pools vary over diurnal (and to a lesser extent seasonal) cycles. There is also some information on the effects of time and height of tide on the extreme values attained and the rates of change of critical parameters, which are accepted as being temperature and oxygen concentration. Most authors have, however, worked in cold climate areas and have limited their data to small numbers of pools, usually situated relatively high on the shore. As a result no clear relation has emerged between pool elevation and the conditions which must be survived by its inhabitants. Similarly, no vertical zonation patterns have been established for the biota of rock pools, in contrast to the well-established patterns for the aerially exposed intertidal community.

The west coast of the Cape Peninsula (South Africa) provides ideal sites for further study, because of the marked contrast between the warm, sunny summer weather and the cool sea conditions. We have investigated relations between the time and height of tide and the daily range of physico-chemical conditions experienced in rock pools at various levels. By recording extreme conditions in pools at different heights and simultaneously noting the biomass and composition of their biota we have attempted to quantify the relations between pool height and physico-chemical stress, and to identify the key physical factors influencing the distributional limits of their inhabitants. We have also compared the distribution pattern of the rock pool biota with that established for aerially exposed intertidal communities.

\section{METHODS}

The study was conducted at Three Anchor Bay $\left(33^{\circ} 54^{\prime} \mathrm{S} 18^{\circ} 23^{\prime} \mathrm{E}\right)$, an exposed shore of ridged Malmesbury shale situated on the Atlantic seaboard of the Cape Peninsula, South Africa. Sea surface temperatures in this area average 11 to $15^{\circ} \mathrm{C}$ in winter and 9 to $13^{\circ} \mathrm{C}$ in summer, when there is coastal upwelling
(Velimirov et al. 1977). Mean daily minimum and maximum air temperatures are 16 to $27^{\circ} \mathrm{C}$ in summer (February), and 8 to $17^{\circ} \mathrm{C}$ in winter (July), corresponding monthly minima and maxima being 11 to $35^{\circ} \mathrm{C}$ and 4 to $25^{\circ} \mathrm{C}$.

Four rock pools of about $1 \mathrm{~m}^{2}$ in area and $30 \mathrm{~cm}$ depth, but situated at different heights representative of the tidal range, were selected for the initial measurements of diumal temperatures and oxygen concentrations. The heights of the pools were estimated using the method outlined by Day (1974). Hourly readings of temperature and oxygen concentration were taken at the centre and mid-depth of each pool using a Yellow Springs Instrument Company model 54A oxygen meter. This was done both during a $24 \mathrm{~h}$ period of neap tides, on 9 to 10 March 1984, when low tide occurred towards the middle of the day and night (1412 and $0111 \mathrm{~h}$ ), and at spring tides, on 16 to 17 March 1984, when the low tides were in the morning and evening ( 0852 and $2105 \mathrm{~h}$ ). On the basis of these readings it was possible to identify periods when physicochemical conditions were most extreme. During subsequent days further measurements were taken at these specific times in 28 additional pools of similar dimensions and situated in the same general area.

Finally, the biota of each pool was sampled by removing all benthic macro-organisms within a randomly placed $0.1 \mathrm{~m}^{2}$ quadrat. The plant and animal material was separated, drained, wet weighed, then identified to species where possible. From lists of species recorded in each pool a presence-absence matrix of 28 columns, representing the pools in order of descending height on the shore, by 33 species (as the rows) was constructed. This matrix was analysed using 2 methods of cluster analysis. The first of these utilized the group average sorting method and Bray-Curtis (1957) measure of similarity to derive a dendrogram showing the percentage similarity between the biota of the various pools. This was complemented by nonmetric multi-dimensional scaling (Field et al. 1982), which uses the same Bray-Curtis similarity matrix to produce an ordination diagram, depicted in a 2-dimensional form.

\section{RESULTS}

\section{Physico-chemical conditions}

The 4 pools in which diurnal changes in temperature and oxygen concentration were monitored were located $73,110,131$ and $170 \mathrm{~cm}$ above chart datum. Over the neap tide of 9 to $10 \mathrm{March}$ the tidal range was $0.7 \mathrm{~m} \mathrm{(0.7} \mathrm{to} 1.4 \mathrm{~m}$ above chart datum), failing to flood the uppermost pool. Air temperatures ranged from $19.0^{\circ} \mathrm{C}$ at $0400 \mathrm{~h}$ to $27.8^{\circ} \mathrm{C}$ at $1300 \mathrm{~h}$. At spring tide, on 
16 to 17 March, the tidal range was $1.6 \mathrm{~m}(0.3$ to $1.9 \mathrm{~m}$ above chart datum), flooding all the pools. Air temperatures reached a maximum of $29.2^{\circ} \mathrm{C}$ at $1300 \mathrm{~h}$ and fell to $19.4{ }^{\circ} \mathrm{C}$ at $0200 \mathrm{~h}$.

Diurnal variations in water temperature in the 4 pools, numbered 1 to 4 in a downshore direction, are shown in Fig. 1. Over neaps (Fig. 1A) the morning high tide splashed into Pool 2, but fell well short of Pool 1, which remained isolated throughout the day. Temperatures in Pool 1 fluctuated smoothly between a peak of $25^{\circ} \mathrm{C}$ at $1500 \mathrm{~h}$ and a trough of $16^{\circ} \mathrm{C}$ at $0400 \mathrm{~h}$ (still well above the sea temperature of 11 to $14^{\circ} \mathrm{C}$ ). In the lower pools temperatures were minimal during flooding, but rose rapidly towards those in Pool 1 as soon as the pools were exposed, again to peak at about $1500 \mathrm{~h}$. As the tide rose during the evening the temperature curves were truncated as the sea reached the pools and rapidly chilled them back to sea temperature. A similar pattern was evident at night, except that with the air cooler and the sun down, temperature changes were less dramatic.

At spring tides (Fig. 1B) a somewhat different pattern was evident. Low tide now occurred early in the day, when both air temperature and solar radiation were on the increase. The temperatures of the pools thus began to climb rapidly from about $0800 \mathrm{~h}$, but each curve was abruptly truncated as the rising tide flooded the pools in ascending order. This depressed the maximum temperatures reached, except possibly in Pool 1, which was only flooded at $1300 \mathrm{~h}$, when it was already approaching its peak temperature. During the evening low tide the temperatures in Pools 2 to 4
Fig. 1. Diumal temperature fluctuations at the centres of 4 rock pools situated $170,131,110$ and $73 \mathrm{~cm}$ above chart datum (Pools 1 to 4 respectively), at Three Anchor Bay, South Africa. (A) Neap tide period on 9 to 10 Mar 1984 ; (B) spring tide period on 16 to 17 Mar 1984.

Horizontal bars indicate darkness
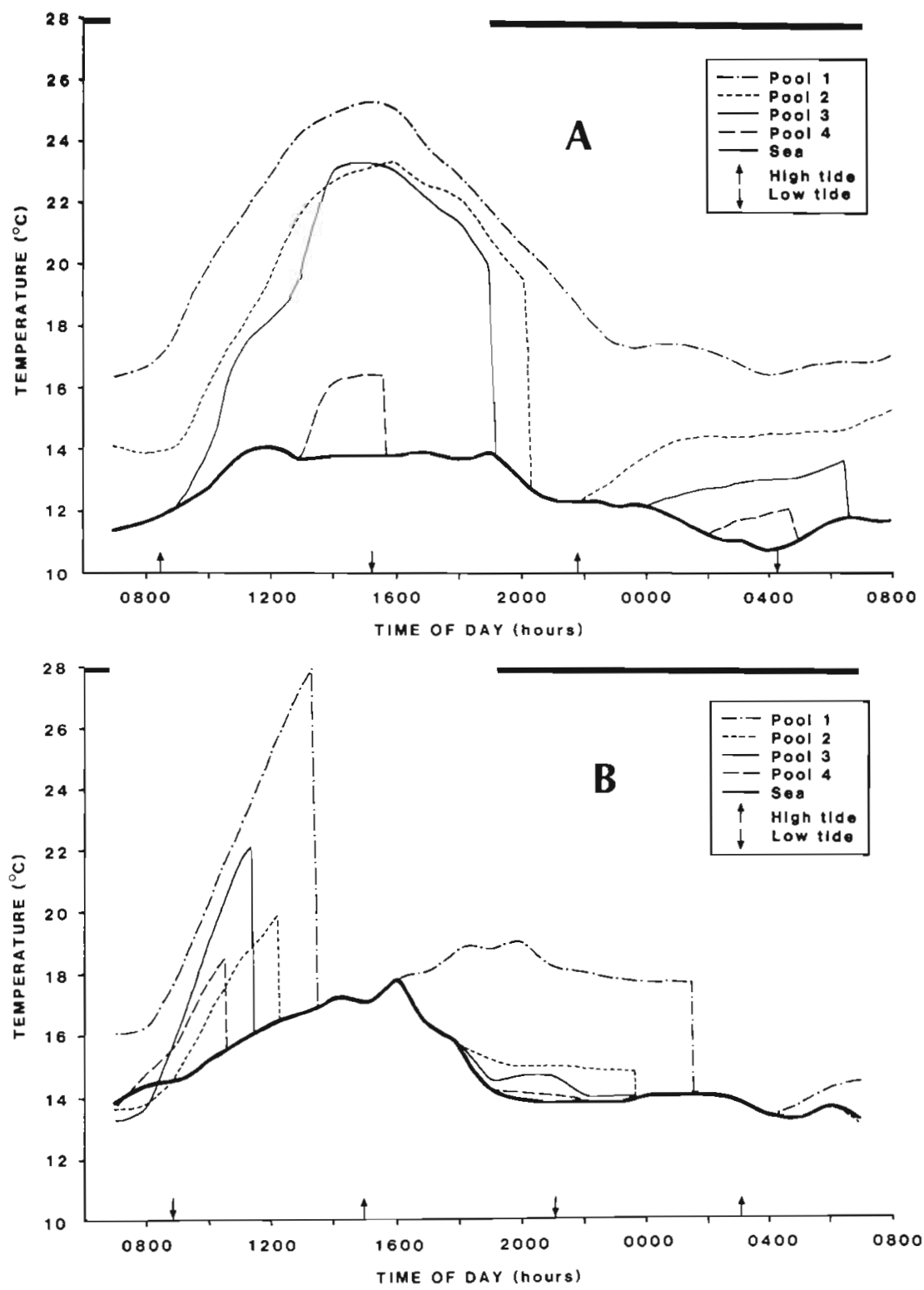
rose only slightly, while that of Pool 1 increased significantly, because, being the earliest to be exposed, it became isolated well before sunset.

The plots showing diurnal variations in oxygen concentration (Fig. 2) display a similar pattern, with maximal values occurring during the day and minima at night. During neap tides (Fig. 2A) Pools 2 and 3 in the midshore experienced prolonged periods of greatly elevated ( $>200 \%$ saturation) oxygen concentration by day, the maxima again occurring at about 1300 h. Pool 4 was exposed for too short a period to show very strong deviations from the sea. At night oxygen concentrations in Pools 2 to 4 fell well below ambient, the amplitude of the lows reflecting those of the daytime highs. Thus Pool 3, although relatively low on the shore, experienced both the highest and lowest oxygen levels recorded. Pool 1, which was completely isolated from the sea, showed only smooth, low amplitude variations in oxygen concentration, the maximum occurring in late afternoon and the minimum late at night.

At spring tides (Fig. 2B) oxygen variations again superficially resemble those of temperature. Peak values occurred in the morning, just before each pool was inundated by the rising tide. This once more resulted in more rapid rates of change than those occurring at neaps, but depressed the maximum values attained.

During the evening low tide oxygen levels fell below those of the sea inmediately after dusk and continued to decline until the pools were inundated by the rising tide. In contrast to temperature, which was most extreme in the highest pools, the highest daytime and lowest nocturnal oxygen concentrations were recorded
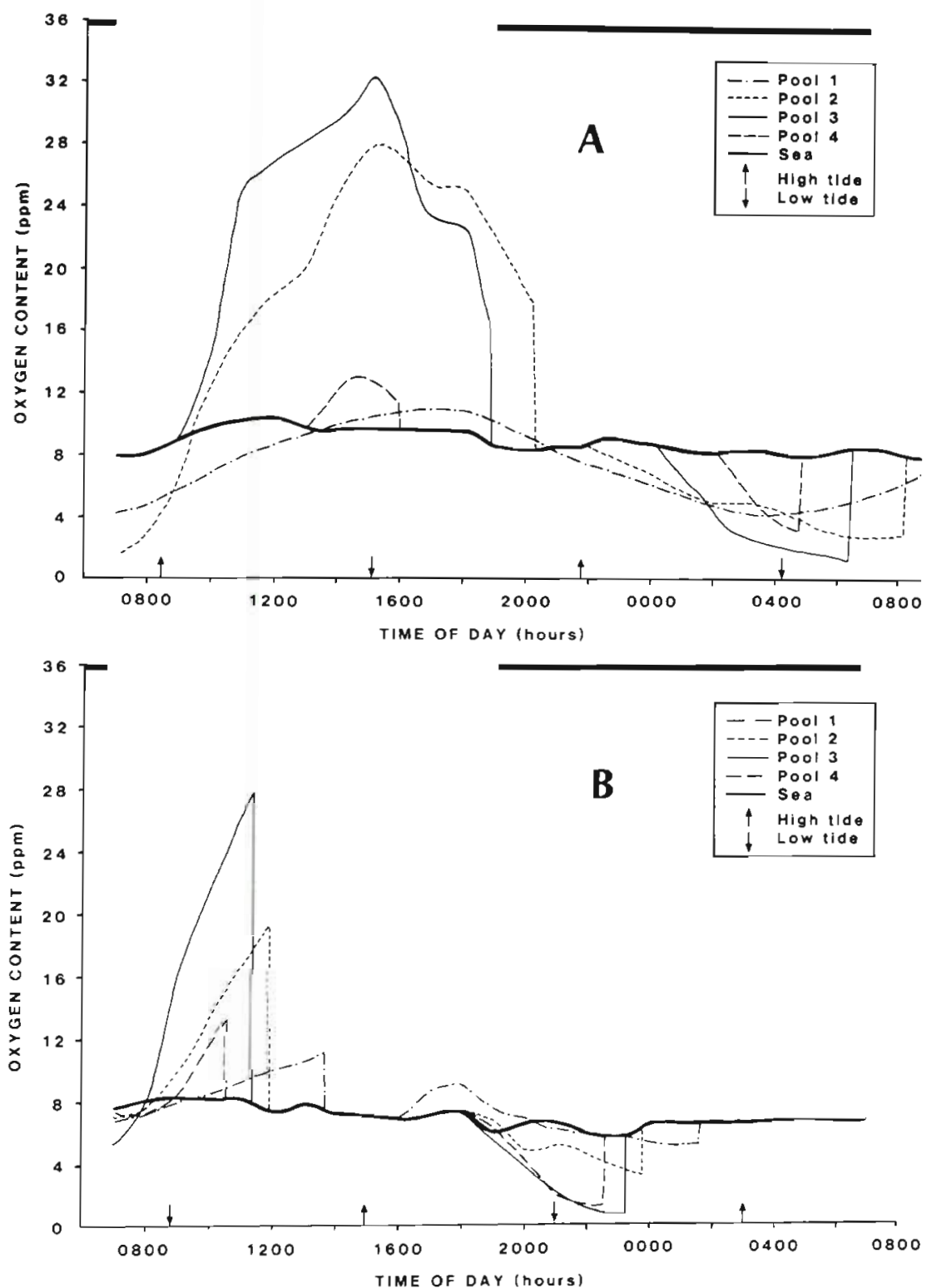

Fig. 2. Diurnal fluctuations in oxygen concentration at the centres of 4 rock pools situated $170,131,110$ and $73 \mathrm{~cm}$ above chart datum (Pools 1 to 4 respectively) at Three Anchor Bay, South Africa. (A) Neap tide period on 9 to $10 \mathrm{Mar}$ 1984; (B) spring tide period on 16 to 17 Mar 1984. Horizontal bars indicate darkness 
in Pool 3. Pools 2 and 1, although successively higher on the shore, showed progressively less overall diurnal range in oxygen content.

From these results we were able to identify 2 periods when physico-chemical conditions in rock pools were at their most extreme. The first, when oxygen levels were minimal, occurred when the pools had experienced their maximum period of nocturnal exposure, i.e. just before dawn or inundation following a nocturnal low tide. The second, when both oxygen and temperature were maximal, occurred just before the pools were flooded following a daytime low tide, or at about $1500 \mathrm{~h}$, if the pools had not been flooded by that time. Since air temperatures in Cape Town seldom fall much below those in the sea, which are depressed by coastal upwelling, temperature minima normally occur during tidal immersion and are thus equal for pools at all levels.

Following this rationale we recorded the peak temperatures and oxygen concentrations attained by a wide range of pools following late morning low tides $(1030$ to $1200 \mathrm{~h})$ and the oxygen minima in the same pools following a night-time $(2300 \mathrm{~h})$ tide and plotted these relative to the height of the pools on the shore. The temperature results are shown in Fig. 3 and clearly indicate that the maximum temperatures attained by rock pools of a given size are related to their height on the shore. The daily temperature minima for all the pools will be the same, providing they are inundated, and also equal to the sea temperature, which is seldom above $14{ }^{\circ} \mathrm{C}$. Pools higher up the shore thus experience progressively larger diurnal temperature ranges. The maximum range at the time of sampling, attained by pools more than $1.5 \mathrm{~m}$ above LWS, was about $17^{\circ} \mathrm{C}$, but will depend upon season and weather conditions.

The maximum and minimum oxygen concentrations attained in pools at different levels (Fig. 4) reveal a

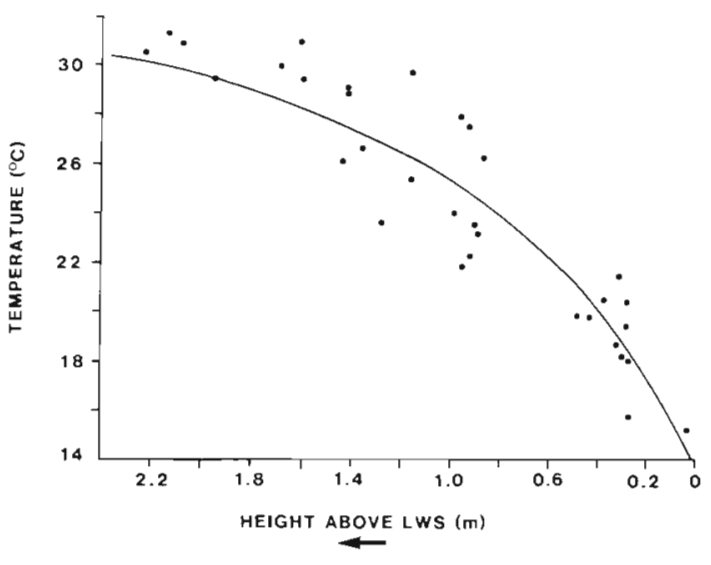

Fig. 3. Maximum temperatures attained by rock pools at Three Anchor Bay, South Africa, plotted against height on the shore, relative to the lowest tide of the month (Mar 1984). The position of the $\mathrm{x}$-axis at $14^{\circ} \mathrm{C}$ represents the mean daily maximum sea surface temperature over the sampling period. Maximum pool temperature $(T)$ is related to height above LWS $(\mathrm{Ht})$ by the equation: $\mathrm{T}=25.4 \mathrm{Ht}^{0.16}\left(\mathrm{r}^{2}=0.74, \mathrm{n}=33\right)$

much more complex and interesting pattern. Peak oxygen values (here expressed as percentage saturation, to correct for the temperature differences between pools) do not occur high on the shore, but rather at about $0.8 \mathrm{~m}$ above LWS. Minimum values were also found at an intermediate level, but occurred lower on the shore than the oxygen maxima, approximately 0.2 to $0.6 \mathrm{~m}$ above LWS (near the LWN mark). In this region most of the pools were only about $10 \%$ saturated immediately before they were inundated. Pools in the mid-tide range ( 0.5 to $1.0 \mathrm{~m}$ above LWS ) thus experienced the most extreme oxygen variations, with levels rising to well over $200 \%$ saturation by day and plunging to less than $20 \%$ saturation at night.
Fig. 4. Maximum ( $\mathbf{0}$ ) and minimum ( $\mathbf{\Lambda}$ ) daily oxygen tensions attained in rock pools at different tidal heights at Three Anchor Bay, South Africa. Maximum values were obtained just before each pool was flooded following a midday low tide, minimum values just before each pool was flooded following a midnight low tide. The separation between the 2 lines thus shows how the daily range of oxygen conditions varies with tidal height

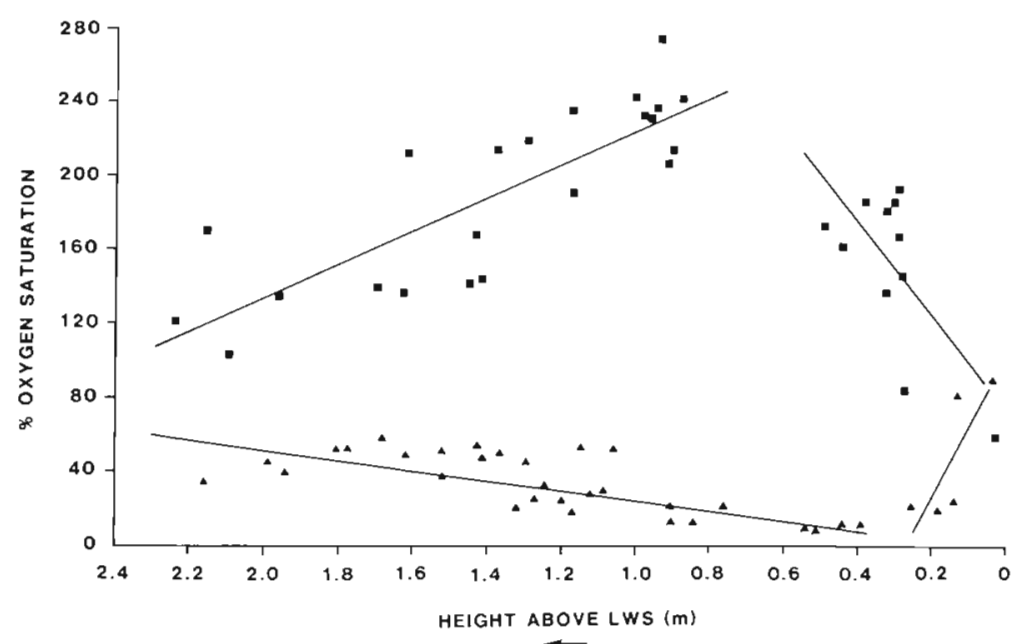




\section{The biota}

There was a clear increase in the biomass of both plants and animals down the shore (Fig. 5). In the midshore zone the biomass of plants was similar to that of animals, but pools both high and low on the shore supported a much larger biomass of animals than plants.

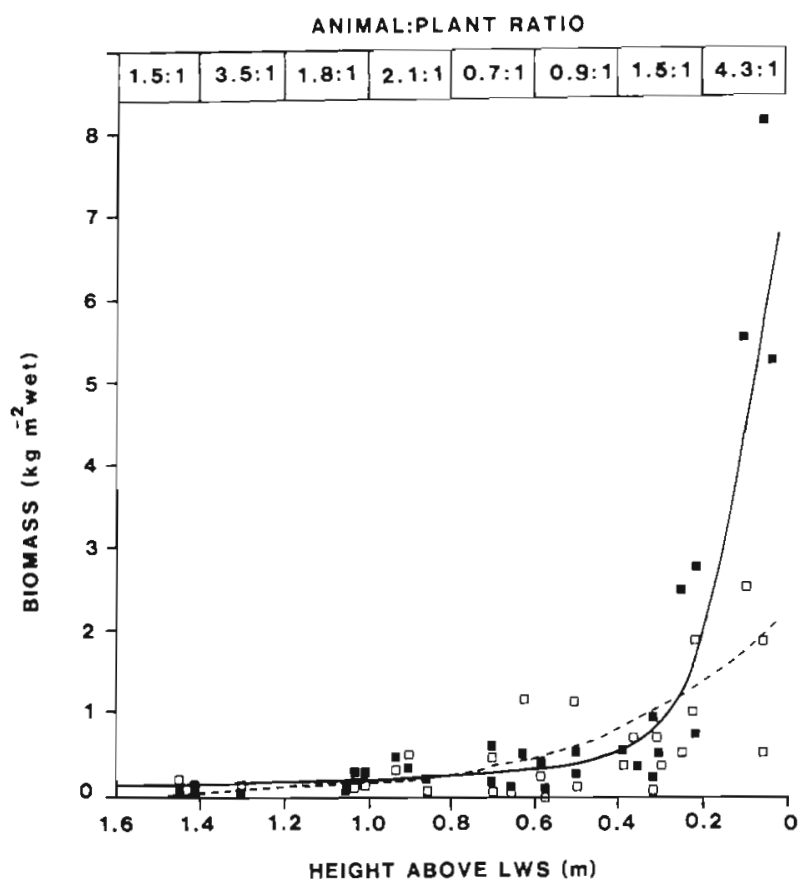

Fig. 5. Wet biomass of plants ( $\square$ and dotted line) and animals (a and solid line) supported by rock pools at Three Anchor Bay, South Africa, relative to their height above the lowest spring tide of the month

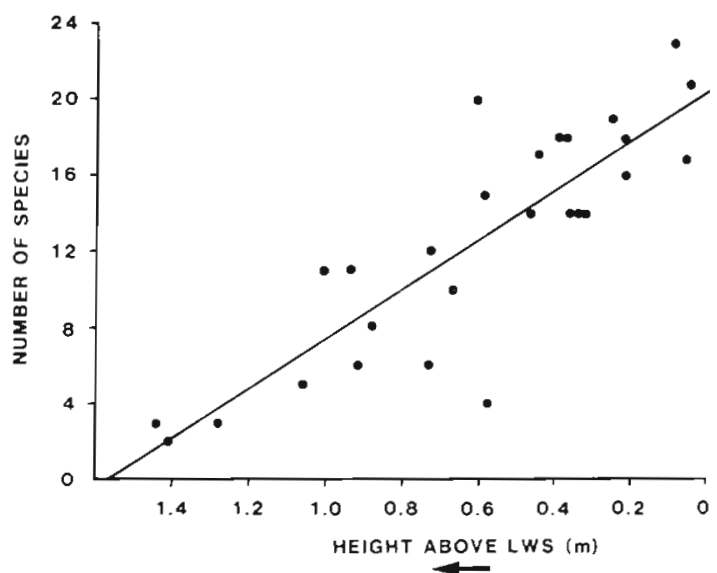

Fig. 6. Numbers of macroscopic (>5 mm) species recorded in rock pools at Three Anchor Bay, South Africa, relative to their height on the shore above the lowest spring tide of the month. The number of species $(N)$ is related to height $(\mathrm{Ht})$ by the equation: $\mathrm{N}=-13.37 \mathrm{Ht}+20.45(\tau=0.84, \mathrm{n}=27)$
There was a linear increase in the number of species recorded per $0.1 \mathrm{~m}^{2}$ of pool area down the shore (Fig. 6). The actual limits of distribution of those species recorded in 2 or more of the pools are shown in Fig. 7. These data suggest that major changes in species composition of rock pool biota occur at, or just above, the major tidal limits of high and low water of spring tides and high and low water of neap tides. Algae and grazing gastropods were the main forms found in upper shore pools, while filter feeding bivalves and sponges dominated the exceptionally large animal biomass in pools close to LWS.

An ordination map depicting the results of multidimensional scaling using a presence: absence matrix of species recorded in each pool is shown in Fig. 8. Clusters of stations were delimited with the aid of a dendrogram (not shown). The pools, which are numbered in sequence from topshore downwards, fell into 3 distinct groups, each with an internal similarity level $>50 \%, 2$ individual pools falling outside the groupings at this level of similarity. With minor exceptions these groups conform with tidal patterns, Group A being situated above HWN, Group B between HWN and LWN and Group C below LWN.

\section{DISCUSSION}

Organisms living in rock pools are protected from desiccation, perhaps the primary factor controlling the distribution of organisms on exposed rock surfaces in the intertidal zone (Newell 1979), but they nevertheless occupy an extremely dynamic habitat. The alternate flooding and isolation of pools by the tide results in fluctuations in temperature which, although dampened relative to those experienced in adjacent aerial habitats, cannot be countered by evaporative cooling (Newell 1979). Rock pool organisms are, moreover, subject to stresses to which aerial forms are seldom exposed, notably large fluctuations in dissolved oxygen concentration. Variations in salinity following precipitation or evaporation may also be more difficult to endure in the aquatic phase than the aerial one.

Our results have demonstrated that complex, but nevertheless predictable, relations exist between the range of physico-chemical conditions experienced in rock pools, their elevation on the shore, the time and height of the tides, the weather conditions and the biota found in the pools. In this respect they confirm the results of investigations of rock pools in other regions (see 'Introduction').

The temperature attained by a pool of fixed size is determined primarily by the duration of exposure and rate of heat input. The first of these is a function of the height of the pool on the shore relative to the tidal 


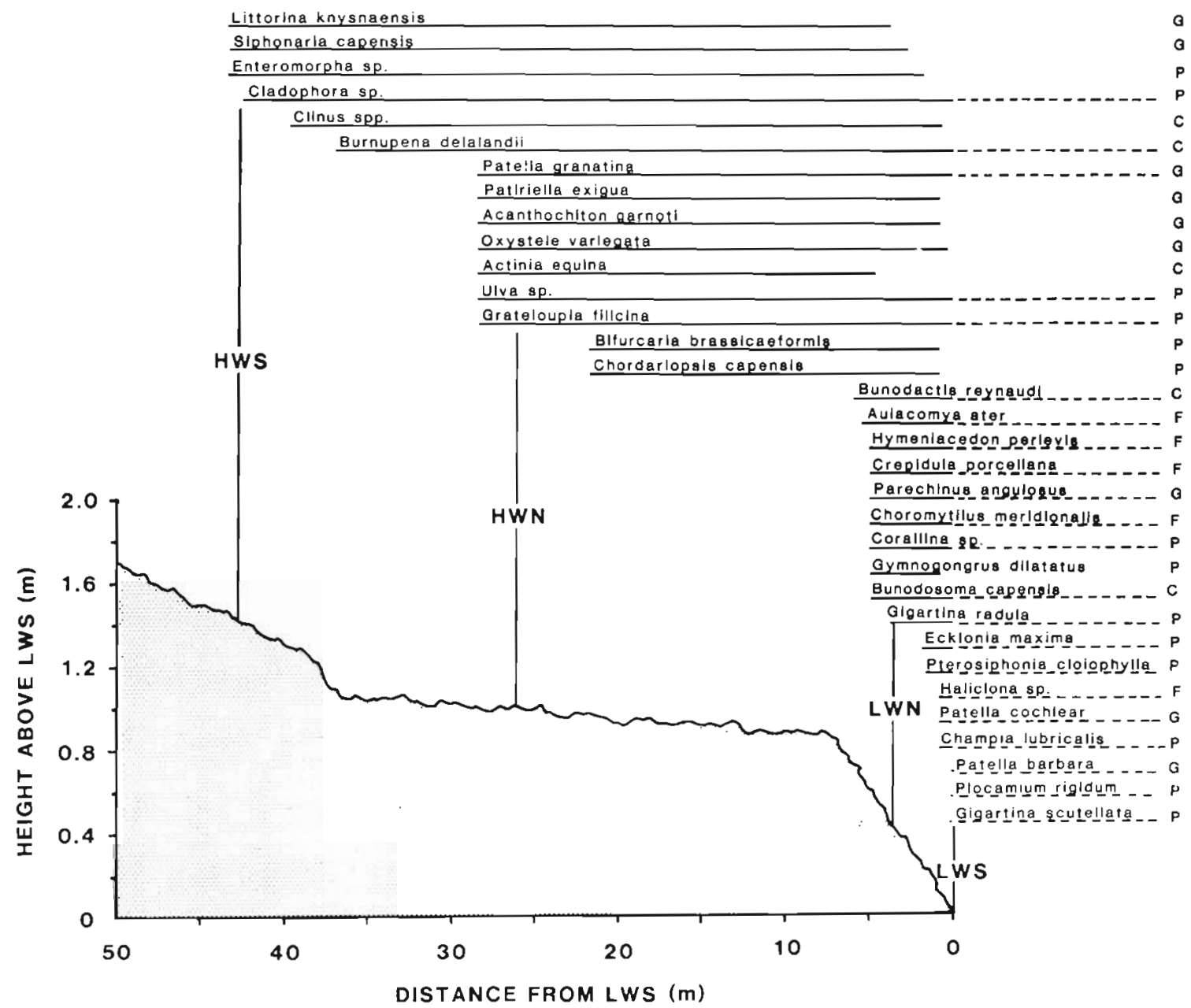

Fig. 7. Distribution range of various rock pool species at Three Anchor Bay, South Africa, in relation to lowest low tide of the month. The code letters to the right indicate trophic groups: $P=$ plant $_{;} G=$ grazer; $C=$ camivore; $F=$ filter feeder. Dotted line indicates extension of range beyond LWS

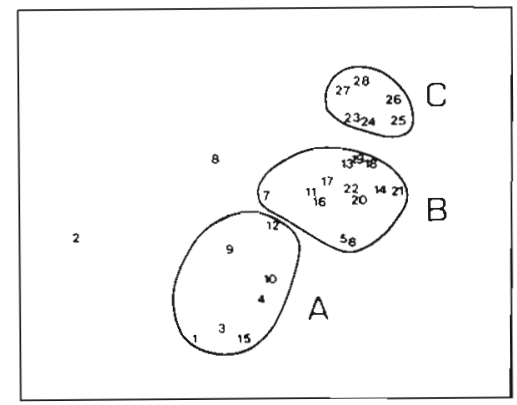

Fig. 8. Ordination of 28 rock pools at Three Anchor Bay, South Africa, in 2 dimensions, using multi-dimensional scaling. Clusters $\mathrm{A}$ to $\mathrm{C}$ were demarcated with the aid of a dendrogram formed by group-average sorting and are generally comprised of pools situated above HWN, between HWN and LWN and below LHN respectively

range at that time. The second is determined by air temperature, intensity of solar radiation and, to a lesser extent, humidity and wind speed. Both air temperature and radiation peaked at about $1300 \mathrm{~h}$ during our study (University of Cape Town Meteorological Station Records). The rate at which the pools are heated thus depends on the relation of the exposure period to the midday heat maximum (Fig. 1). Pools exposed over the hottest part of the day (Fig. $1 \mathrm{~A}$ ) reached their temperature maximum at about $1500 \mathrm{~h}$, as they continued to absorb heat from the rocks for some time after air temperatures had started to drop. Morris \& Taylor (1983) report a similar situation with pool temperatures peaking around mid-afternoon, 1 to $2 \mathrm{~h}$ after the highest air temperature, and Daniel \& Boyden (1975) observed temperature maxima in pools between 1400 and $1500 \mathrm{~h}$. In the Baltic, Ganning (1971) found maximum temperatures in the pools to occur at $1300 \mathrm{~h}$, and also noted that the heat stored in the bedrock is important in delaying a temperature decline in the rock pools. Thus, the peak temperature attained is a direct function of height on the shore (and hence duration of exposure). The same principles hold true during a 
nocturnal tide, except that, because there is less heat input, the temperature increments are far smaller than by day.

As the times of low tide progress towards morning and evening a different pattern emerges, in which the temperature increases are truncated by the rising tide (Fig. 1B). This depresses the maximum values, but may introduce a different stress on the biota in that rates of temperature change become more acute. (In Cape Town spring low tides always occur in the morning and late evening, so that pools low on the shore are never exposed during the heat of the day.)

The most extreme conditions experienced by rock pool organisms occur when the pools are flooded just as they reach their maximum temperatures - since both the highest temperatures and fastest rates of change occur simultaneously at this time. Pool 1 (Fig. 1B) experienced just this situation, but it would occur on successively later days in pools at lower levels. Fig. 3 gives an indication of the maximum temperatures reached by pools during our study period relative to their height on the shore. A similar relation probably persists throughout the year, but the steepness of the curve will depend upon weather and thus season (see Morris \& Taylor 1983).

Changes in dissolved oxygen concentration in rock pools result mostly from the metabolic activities of the organisms themselves (see Pyefinch 1943, Daniel \& Boyden 1975, Morris \& Taylor 1983). The effects of time and height of tide on oxygen fluctuations in pools at differing tidal levels were similar to those described for temperature, except that oxygen levels declined when the pools were isolated at night. As the rates of change are dependent upon the biota the extremes reached were related to pool height in a quite different pattern. Pools high on the shore supported a sparse biota (Fig. 5), so experienced only minor diurnal variations in oxygen concentration. Lower on the shore plant, and particularly animal, biomass increased dramatically, so that although the pools were isolated for shorter periods, the extremes in oxygen concentration increased in amplitude. Finally an inflexion point was reached, beyond which exposure times were so short that the diurnal range of oxygen concentrations declined once more (Fig. 4). This belies the conclusions reached by some earlier authors (e.g. Pyefinch 1943, Naylor \& Slinn 1958) that conditions consistently becorne more extreme the further up the shore.

The most extreme maximum and minimum levels of oxygen saturation occurred in pools at different tidal heights (Fig. 4). This undoubtedly resulted from the higher animal biomass in lowshore pools (Fig. 5). The respiratory activity of the very large animal standing stock in the lowest pools probably depressed the oxygen maximum during the day and pushes the point at which minimum levels were reached at night to the right (downshore). Many of the lowshore pools experienced oxygen minima of about $10 \%$ saturation, but none became anoxic, indicating that the biota may be regulated at a level which will not completely deoxygenate its environment. Similar oxygen concentrations, some as low as $3 \%$ saturation (Daniel \& Boyden 1975), have been recorded elsewhere in heavily weeded pools following prolonged nocturnal isolation.

There was a steady increase in number of species (or taxa) down the shore and major changes in species composition took place at specific tidal levels (Fig. 7). Both trends are similar to that observed for exposed intertidal rock surfaces (for review see Newell 1979). This zonation pattern suggests that specific limiting conditions come into force at different tidal levels. Pools below LWN can be colonized by species that are not tolerant of extreme temperature variations, particularly as they are not isolated during the hottest part of the day (spring low tides always being in the morning and evening). The extremely low oxygen concentrations experienced during the night, however, probably prevent some sublittoral species from penetrating this environment. The dominant species in biomass terms in such pools are filter feeding bivalves, which can survive low oxygen concentrations, but require a regular exchange of water to renew their food supplies. Between HWN and LWN pools experience maximum diurnal fluctuations in oxygen concentration (frequently $<20 \%$ to $>200 \%$ saturation) (Fig. 4) as well as increased temperature variations (Fig. 3), but these are short term as the pools are immersed by every tide. Above HWN conditions of oxygen availability become less extreme, so that the further decline in species diversity at this point must be due to other factors.

Classification of the communities colonizing intertidal rock pools at various elevations by means of a similarity matrix indicates that the communities show clear vertical zonation patterns. Three zones are apparent, one below LWN, the second between LWN and HWN and the third above HWN. These zones correspond closely to the well-established patterns for aerially exposed communities on rocky shores, in which 3 strata, the sublittoral, eulittoral and littoral fringe, with similar boundaries, are universally recognized (Newell 1979).

Acknowledgements. We are indebted to Paul Baines and Steve Hawkins for assistance with the fieldwork, Di Gianakouras for her help with the figures and Sandy Tolosana for typing the final manuscript. Our thanks also to Tim Crowe, Steve Hawkins and John Field for their comments and suggestions. Financial support was provided by a C.S.I.R. postgraduate research bursary to the senior author and via the Benguela Ecology Programme of the South African National Committee for Oceanographic Research. 


\section{LITERATURE CITED}

Ambler, M. P., Chapman, V. J. (1950). A quantitative study of some factors affecting tide pools. Trans. R. Soc. N. Z. 78: $394-409$

Bray, J. R., Curtis, J. T. (1957). An ordination of the upland forest communities of Southern Wisconsin. Ecol. Monogr. 27: $325-349$

Daniel, M. J., Boyden, C. R. (1975). Diurnal variations in physico-chemical conditions within intertidal rock pools. Fld. Stud. 4: 161-176

Day, J. H. (1974). A guide to marine life on South African shores, Balkema, Cape Town

Field, J. G., Clarke, K. R., Warwick, R. M. (1982). A practical strategy for analysing multispecies distribution patterns. Mar. Ecol. Prog. Ser. 8: 37-52

Ganning, B. (1971). Studies on chemical, physical and biological conditions in Swedish rockpool ecosystems. Ophelia 9: 51-105

Johnson, D. S., Skutch, A. F. (1928). Littoral vegetation on a headland of Mt. Desert Island, Maine. II. Tide-pools and the environment and classification of submersible plant communities. Ecology 9: 307-338
Klugh, A. B. (1924). Factors controlling the biota of tide pools. Ecology 5: 192-196

Morris, S., Taylor, A. C. (1983). Diurnal and seasonal variation in physico-chemical conditions within intertidal rock pools. Estuar. coast. Shelf Sci. 17: 339-355

Naylor, E., Slinn, D. J. (1958). Observations on the ecology of some brackish water organisms in pools at Scarlett Point, Isle of Man. J. Anim. Ecol. 27: 15-25

Newell, R. C. (1979). Biology of intertidal animals. Marine Ecological Surveys, Faversham

Pyefinch, K. A. (1943). The intertidal ecology of Bardsey Island, North Wales, with special reference to the recolonization of rock surfaces, and the rock-pool environment. J. Anim. Ecol. 12: 82-108

Stephenson, T. A., Zoond, A., Eyre, J. (1934). The liberation and utilization of oxygen by the population of rock-pools. J. exp. Biol. 2: 162-172

Velimirov, B., Field, J. G., Griffiths, C. L., Zoutendyk, P. (1977). The ecology of kelp bed communities in the Benguela upwelling system. Helgoländer Meeresunters. 30: 495-518

This paper was presented by Professor J. G. Field; it was accepted for printing on November 22, 1985 